Article

\title{
In Situ Synthesis of Silver Nanoparticles on Cellulose Fibers Using D-Glucuronic Acid and Its Antibacterial Application
}

\author{
Guangxue Chen, Linjuan Yan, Xiaofang Wan *, Qiankun Zhang and Qing Wang * \\ State Key Laboratory of Pulp and Paper Engineering, South China University of Technology, Guangzhou 510640, \\ China; chengx@scut.edu.cn (G.C.); felinjuan1025@mail.scut.edu.cn (L.Y.); 201820125931@mail.scut.edu.cn (Q.Z.) \\ * Correspondence: wangqing@szyuto.com (Q.W.); wanxf@scut.edu.cn (X.W.)
}

Received: 25 August 2019; Accepted: 19 September 2019; Published: 23 September 2019

check for updates

\begin{abstract}
The development of ecofriendly procedures to avoid the use of toxic chemicals for the synthesis of stable silver nanoparticles (AgNPs) is highly desired. In the present study, we reported an eco-friendly and green technique for in situ fabrication of AgNPs on bleached hardwood pulp fibers (bhpFibers) using D-glucuronic acid as the only reducing agent. Different amounts of D-glucuronic acid were introduced and its effect on the size and distribution of AgNPs on the bhpFibers was discussed. The morphology and structures of bhpFibers@AgNPs were proved by electron microscope-dispersive spectroscopy (SEM-EDS), X-ray diffraction (XRD), Fourier transform infrared (FT-IR) and X-ray photoelectron spectroscopy (XPS). Then, a series of bhpFibers@AgNPs with different AgNPs loadings were also prepared by adjusting the concentration of the $\mathrm{AgNO}_{3}$ solution. After a papermaking process via vacuum filtration, the prepared papers displayed an outstanding antibacterial performance against Escherichia coli (gram -negative) and Staphylococcus aureus (gram-positive). It is foreseeable that the bhpFibers@AgNPs have a promising application in the field of biomedical.
\end{abstract}

Keywords: green synthesis; silver nanoparticles; D-glucuronic acid; cellulose fibers; antibacterial properties

\section{Introduction}

AgNPs have been widely accepted as the most efficacious metal with antimicrobial properties [1-5]. However, the dissociative AgNPs or silver ions may cause inevitable harm to human health and the environment, which greatly hinders the practical application [6]. Therefore, AgNPs have generally been in situ generated onto various polymeric matrices [7-10]. These silver-based nanocomposites possess excellent antimicrobial properties against a wide scope of pathogens, which play vital roles in medical antibacteria [11-13], wound treatment [14,15], food packaging and textiles [16,17]. Since the size, morphology and structure of AgNPs are strongly related to their antimicrobial properties, the synthesis process should be technologically controlled.

Among all the polymer matrices, cellulose has attracted much attention due to the advantages of abundant resources [18-21] and rich hydroxyls in its molecular structure [22,23]. Recently, methods have been developed for the fabrication of cellulose/AgNP nanocomposites. Zhu et al. [24] presented an in situ synthesis of AgNPs in pristine cellulose fibers using $\mathrm{NaBH}_{4}$ as the reduction agent. The mean size and size distribution of AgNPs were adjusted by changing the concentration of $\mathrm{NaBH}_{4}$. Maria et al. [25] developed bacterial cellulose/silver nanocomposites based on different reductants of hydrazine and hydroxylamine, with the help of such additional agents as gelatin or polyvinylpyrrolidone. Li et al. [26] fabricated cellulose-silver nanocomposites using ethylene glycol (EG) as a reducing agent with a 
microwave-assisted method. Clearly, the use of organic solvents or the use of toxic chemicals as reducing agents during the preparation are unfavorable for the environment, which largely limits their actual application in biomedical fields. Thus, non-toxic green reductants such as glucose [27] and ascorbic acid are commonly chosen for the synthesis of AgNPs in matrices. However, due to the weak reduction of these reducing agents, larger particle sizes or clusters of AgNPs in cellulose have been observed, which lead to poor antibacterial effects [28]. For example, Li et al. [29] found that polyhedral silver particles with a size of $250 \mathrm{~nm}$ exhibited relatively poor dispersion in the cellulose matrix when using ascorbic acid as a reducing agent. In order to further improve the greenness of the in situ generation of AgNPs, using some biological substances, including plant and plant extracts [30,31], as reducing agents has become a new trend. Aladpoosh et al. [32] prepared AgNPs on cotton fabric using ashes of $S$. rosmarinus. The results showed that aggregation of particles in the matrix was unavoidable. Sri Ramkumar et al. [33] first prepared a seaweed extract that was obtained from seaweed by using a mixer grinder, then AgNPs were synthesized by bio-reduction of $\mathrm{AgNO}_{3}$ with the prepared seaweed extract. It is evident that the introduction of these plant reducing agents might cause unexpected aggregation of AgNPs and cumbersome processes. Therefore, it is still a challenge to prepare the AgNPs with small size and uniform distribution in the matrix with green and ecofriendly techniques.

D-glucuronic acid (DLA) might be a most attractive candidate for the synthesis of silver nanoparticles among these chemical reducing agents because of its outstanding features. First, DLA is abundant in many biological systems and is non-toxic [34], which is crucial for 'green chemistry '. Besides, DLA has abundant hydroxyl groups and a terminal aldehyde group in its units [35,36], which might be exploited as glucose. Most of all, DLA is water soluble and possesses negatively charged carboxyl groups, which might electrostatically interact with $\mathrm{Ag}^{+}$and promote the distribution of $\mathrm{Ag}^{+}$in the cellulose matrix [36,37]. It also has been reported that DLA was able to reduce $\mathrm{Cr}^{+5}$ to $\mathrm{Cr}^{+3}$ [38]. From this point, we can except that the DLA can also be used to reduce silver ions to AgNPs on cellulose fibers.

Herein, a one-step green hydrothermal technique for in situ fabrication of AgNPs on bleached hardwood pulp fibers (bhpFibers) was proposed by only using DLA as the reducing agent. Different amounts of DLA were introduced and its effect on the size and distribution of AgNPs on the bhpFibers was discussed. Surface morphology and structures of bhpFibers before and after surface modification were characterized using SEM images, XRD patterns, FT-IR spectra and EDS mapping. Then, a series of bhpFibers@AgNPs with different AgNPs loadings were also prepared by adjusting the concentration of the $\mathrm{AgNO}_{3}$ solution. After the papermaking process, the antibacterial properties of bhpFibers@AgNPs against the Escherichia coli (gram-negative) and Staphylococcus aureus (grampositive) were separately investigated.

\section{Experimental}

\subsection{Materials}

A pulp board made from poplar was supplied by Yueyang Paper Co., Ltd., Yueyang, China. Silver nitrate $\left(\mathrm{AgNO}_{3}, \mathrm{AR}\right)$ was purchased from Sinopharm Chemical Reagent $\mathrm{Co}$, Ltd. (Shanghai, China). The ammonia solution $\left(\mathrm{NH}_{3} \cdot \mathrm{H}_{2} \mathrm{O}, 25 \mathrm{wt} \%\right)$ was provided by Guangzhou Chemical Reagents Factory (Guangzhou, China). Sodium hydroxide ( $\mathrm{NaOH},>98 \%$ ) and D-glucuronic acid (DLA) were obtained from Sinopharm Chemical Reagent Company (Shanghai, China). All the reagents were analytical purity used without further purification. All the water used was deionized water.

\subsection{Pretreatment of Bleached Hardwood Pulp}

The bleached hardwood pulp was first defibered $(100 \mathrm{rpm} / \mathrm{min})$ using a fluffer to separate the interwoven fibers in water without altering the original structure of the fibers. Then bleached hardwood 
pulp fibers (bhpFibers) with a beating degree of $48^{\circ} \mathrm{SR}$ could be obtained after the beat with a speed of 25,000 rpm by the PFI pulping machine (Mark VI, 621, Hamjern Maskin, Oslo, Norway).

\subsection{Synthesis of bhpFibers@AgNPs}

The bhpFibers@AgNPs were prepared through reduction of AgNPs in situ on bhpFibers (Scheme 1). In a typical procedure, $0.2 \mathrm{~g}$ of dried bhpFibers were dispersed in $30 \mathrm{~mL}$ of deionized water. Then, $10 \mathrm{~mL}$ of $\mathrm{Ag}\left(\mathrm{NH}_{3}\right)_{2}{ }^{+}$solutions with appropriate concentrations were added into the above suspension and transferred to the refrigerator overnight. Subsequently, $10 \mathrm{~mL}$ of different concentrations $(0,0.1$, $0.2,0.4$ and $0.6 \mathrm{mg} / \mathrm{mL}$ ) of DLA solutions were dropwise introduced in 20 minutes and conducted for $2 \mathrm{~h}$ at $50{ }^{\circ} \mathrm{C}$. The reaction mixtures were then centrifuged $(8000 \mathrm{rpm}, 3 \mathrm{~min}$ ) and rinsed with deionized water three times to obtain bhpFibers@AgNPs composites.

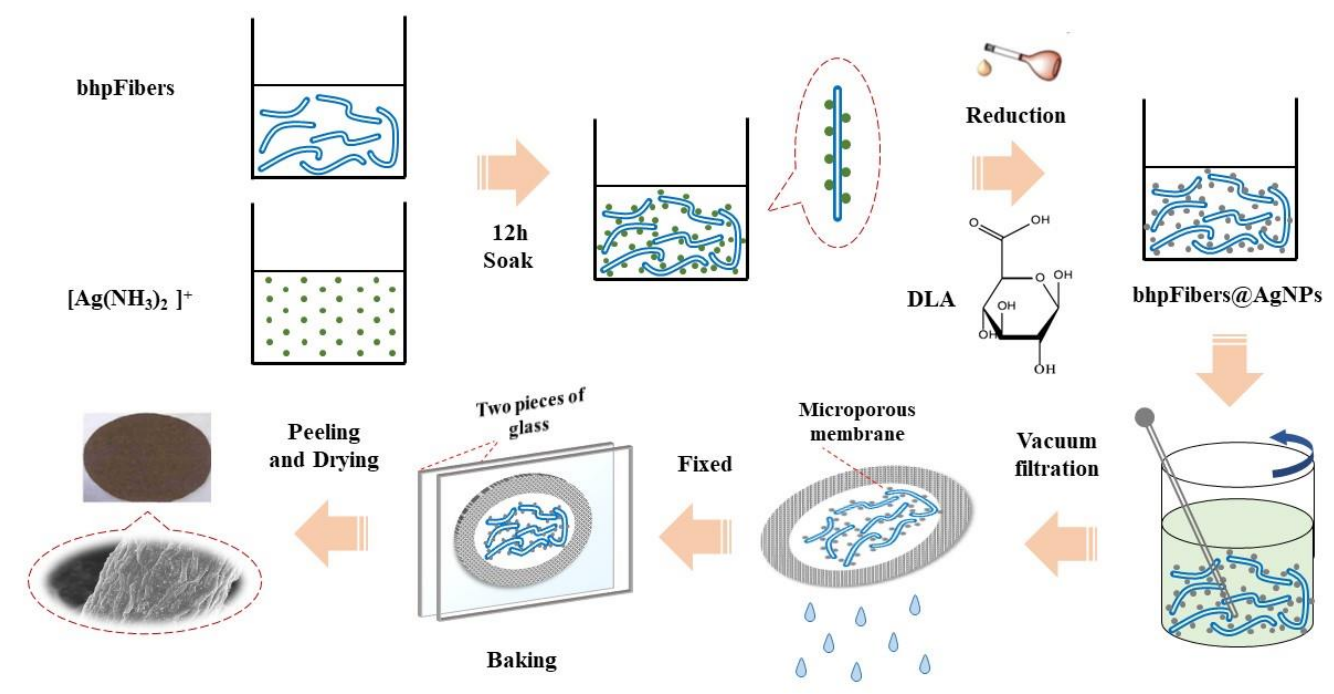

Scheme 1. Schematic of the fabrication of bhpFibers@AgNPs and bhpFibers@AgNP-based paper. AgNPs: Stable silver nanoparticles; bhpFibers: Bleached hardwood pulp fibers.

The $\mathrm{Ag}\left(\mathrm{NH}_{3}\right)$ solutions were prepared by adding $25 \mathrm{wt} \%$ ammonia water dropwise into 20,40 , 60 and $80 \mathrm{mM}$ silver nitrate solutions until the $\mathrm{pH}$ of the mixtures was about 11. A few drops of $\mathrm{NaOH}$ were added to the obtained $\mathrm{Ag}\left(\mathrm{NH}_{3}\right)_{2}{ }^{+}$solutions to adjust the $\mathrm{pH}$ value to 11.5. AgNPs on bhpFibers were synthesized according to the following reactions:

$$
\begin{gathered}
\mathrm{AgNO}_{3}+2 \mathrm{NH}_{3} \cdot \mathrm{H}_{2} \mathrm{O} \rightleftharpoons \mathrm{Ag}\left(\mathrm{NH}_{3}\right)_{2}{ }^{+}+\mathrm{NO}_{3}{ }^{-}+2 \mathrm{H}_{2} \mathrm{O} \\
2\left[\mathrm{Ag}\left(\mathrm{NH}_{3}\right)_{2}\right] \mathrm{OH}+\mathrm{C}_{6} \mathrm{H}_{10} \mathrm{O}_{7}(\mathrm{DLA}) \rightleftharpoons \mathrm{C}_{5} \mathrm{H}_{9} \mathrm{O}_{6} \mathrm{COONH}_{4}+2 \mathrm{Ag} \downarrow+3 \mathrm{NH}_{3}+\mathrm{H}_{2} \mathrm{O}
\end{gathered}
$$

\subsection{Fabrication of bhpFibers@AgNP-based paper}

As shown in Scheme 1, the bhpFibers@AgNP-based paper was fabricated via a vacuum filtration process. Typically, the prepared bhpFibers@AgNPs was dispersed in $100 \mathrm{~mL}$ deionized water to form a stable pulp suspension under gentle stirring. Then, the suspension was poured into the filtration funnel with a $\Phi=0.22 \mu \mathrm{m}$ microporous membrane. After being vacuum-dried at $60{ }^{\circ} \mathrm{C}$ for $12 \mathrm{~h}$, the bhpFibers@AgNP-based paper was successfully prepared. A series of papers with different amounts of AgNPs were also prepared by adjusting the concentration of silver ions in the solution.

\subsection{Characterization}

Morphological characteristics and energy dispersive spectroscopy (EDS) were captured with emission scanning electron microscopy (SEM, Zeiss Merline, Oberkochen, Germany). Crystal structures were performed in the range of $4^{\circ}$ to $90^{\circ}$ on X-ray diffraction (XRD, Philips PW3040/00 X'Pert MPD, 
Westborough, MA, USA) using a diffractometer with $\mathrm{Cu} \mathrm{K} \alpha$ radiation at the $3 \mathrm{~kW}$. Chemical structures were characterized by FT-IR spectra (FTIR-ATR, Bruker VerTex 70, Billerica, Massachusetts, Germany). Chemical compositions were performed on X-ray photoelectron spectroscopy (XPS, Escalab 250 spectrometer, Thermo Electron Corporation, Waltham, MA, America). The thermal gravimetric analyses were investigated by a TGA Instruments (TGA, TA Q500, New Castle county, Delaware, America) heating from 25 to $700{ }^{\circ} \mathrm{C}$ with a heating rate of $10{ }^{\circ} \mathrm{C} / \mathrm{min}$ in a nitrogen atmosphere at a flow rate of $40 \mathrm{~mL} \mathrm{~min}^{-1}$. The silver content was measured by inductively coupled plasma atomic emission spectrometry (ICP-ms, Hitachi Z-2000, Tokyo, Japan).

\subsection{Antimicrobial Activity Test}

Antibacterial detections of the solid plate medium (inhibition zone measurement) are as follows: $10 \mathrm{~mL}$ of the melted solid Luria-Bertani (LB) medium was poured into a Petri dish (90 mm in diameter) before waiting for solidification. Then, Escherichia coli (E. coli) DH5 $\alpha$ or Staphylococcus aureus (S. aureus) was cultured in a liquid LB medium at $220 \mathrm{rpm}$ and $37^{\circ} \mathrm{C}$ until the optical density (OD) 600 was about 0.6 , and the concentration of bacteria reached a 108 colony-forming unit $(\mathrm{CFU}) / \mathrm{mL}$. The obtained $E$. coli or $S$. aureus suspension was taken out to be spread on LB agar plates three times with sterile tweezers. Finally, the prepared bhpFiber-based paper and bhpFibers@AgNP-based paper were placed on the culture medium for full contact. The inoculated microorganisms were cultured at $37^{\circ} \mathrm{C}$ for 24 hours. The antibacterial property of the composites paper was evaluated by the size of the inhibitory zone.

\section{Results and Discussion}

\subsection{Effect of DLA on in-situ preparation of AgNPs on bhpFibers}

SEM was used as a powerful tool to vividly illustrate the morphologies of bhpFibers before and after surface modification. The morphological features and particle size distribution of AgNPs that varied with the concentration of DLA are exhibited in Figure 1 and Figure S1; the pristine bhpFibers in Figure 1a are interwoven by a three-dimensional network composed of interpenetrated cellulose fibers. The interconnected structure increased the fibers' surface roughness, affording good support for the anchoring of AgNPs. After in situ reduction of AgNPs without the aid of DLA, the bhpFiber surfaces were distributed with obviously large particles or clusters of AgNPs of $158.59 \mathrm{~nm}$, as shown in Figure $1 \mathrm{~b}$ and Figure S1b. When the concentration of DLA was $0.1 \mathrm{mg} / \mathrm{mL}$, the AgNPs with a smaller size of average diameter $34.47 \mathrm{~nm}$ gradually appeared in Figure 1c and Figure S1c, in which most of the particles were spheres, but there still existed some large aggregated silver particles. When the DLA amount increased to $0.2 \mathrm{mg} / \mathrm{mL}$, the obtained nanoparticles of bhpFibers had a uniform size distribution and an average diameter of $36.27 \mathrm{~nm}$, as shown in Figure 1d and Figure S1d; they were all spheres and well separated from each other owing to the sufficient DLA molecules, suggesting that the addition of DLA was beneficial for the reduction of aggregated particles and the formation of nanoparticles with uniform and small particle size. With the amount of DLA increasing to 0.4 and $0.6 \mathrm{mg} / \mathrm{mL}$, silver nanoparticles with a larger size, of average diameters $56.13 \mathrm{~nm}$ and $60.82 \mathrm{~nm}$, were prepared on bhpFibers as shown in Figure 1e,f and Figure S1e,f. This might be due to more reducing agents causing faster reduction of $\mathrm{Ag}\left(\mathrm{NH}_{3}\right)_{2}{ }^{+}$and then forming large AgNPs [27]. Figure 1g shows intuitively the particle size of AgNPs on bhpFibers under different amounts of DLA, indicating that the appropriate concentration of DLA can be exploited to control the different sizes of AgNPs. Meanwhile, the smaller AgNPs with larger specific surface areas are accessible for the interaction between AgNPs and bacteria, affording higher antimicrobial effects than larger AgNPs [28]. Based on the results of Figure $1,0.2 \mathrm{mg} / \mathrm{mL}$ of DLA was conducive to the generation of AgNPs with the smallest particle size and uniform distribution on bhpFibers. Compared to the silver particles (80-120 nm) reduced by glucose [27,39], DLA acts as a reducing agent to achieve smaller particle size $(36.27 \mathrm{~nm})$ and better dispersion of silver nanoparticles in the cellulose matrix. This may be because DLA molecules could bind to Ag ions through carboxyl group chelation, which facilitates the reduction of Ag ions [40]. 

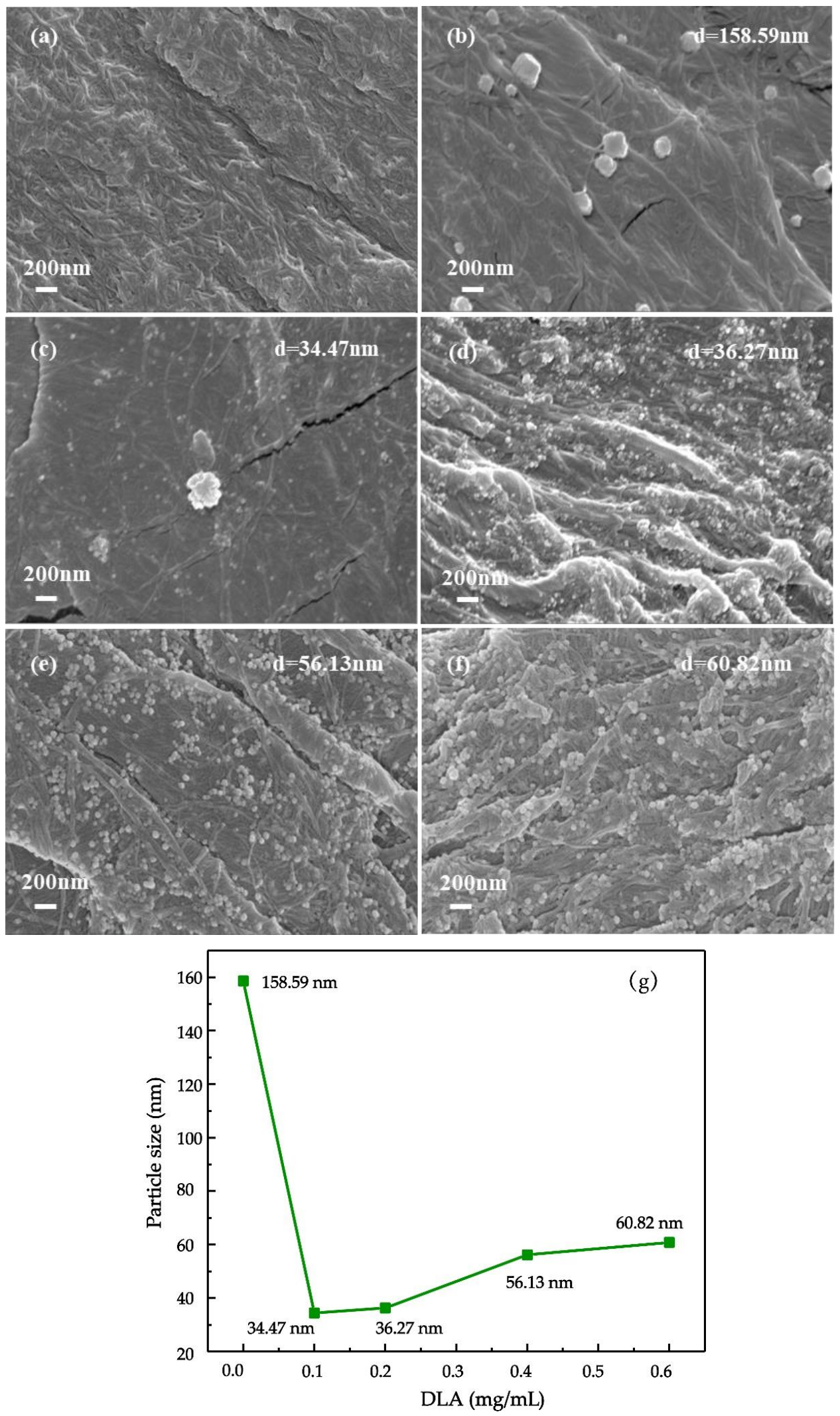

Figure 1. The SEM images of (a) bhpFibers and bhpFibers@AgNP-based paper prepared by $20 \mathrm{mM}$ $\mathrm{AgNO}_{3}$ and different concentrations of DLA: (b) $0 \mathrm{mg} / \mathrm{mL}$, (c) $0.1 \mathrm{mg} / \mathrm{mL}$, (d) $0.2 \mathrm{mg} / \mathrm{mL}$, (e) $0.4 \mathrm{mg} / \mathrm{mL}$ and (f) $0.6 \mathrm{mg} / \mathrm{mL} ;(\mathrm{g})$ silver particle sizes at different concentrations of DLA. 


\subsection{Characterization of the Pristine bhpFibers and bhpFibers@AgNPs Composites}

The crystalline phases of pristine bhpFibers and bhpFibers@AgNP-based paper were characterized by X-ray diffractometry (XRD), shown in Figure 2a. The XRD results show that the bhpFibers had three diffraction characteristic peaks at $2 \theta=14.8,16.5$ and 22.5 corresponding to the typical $(1 \overline{1} 0)$, (110) and (200) planes of cellulose fibers (JCPDS50-0926), respectively [41]. Compared with bhpFibers, the bhpFibers@AgNPs showed typical XRD pattern of Ag nanocrystals on different crystal planes. Moreover, there were five peaks at $2 \theta=38.1^{\circ}, 44.3^{\circ}, 64.4^{\circ}, 77.5^{\circ}$ and $81.6^{\circ}$ in the patterns. These peaks were in accordance with the JCPDS database (No. 89-3722), which corresponded to the (111), (200), (220), (311) and (222) lattice planes of Ag [42], suggesting the synthesis of silver in the crystalline state by using DLA as the reducing agent was successful. In addition, no typical peaks of substance such as $\mathrm{Ag}_{2} \mathrm{O}$ were observed, demonstrating that the pure AgNPs were synthesized on the surface of bhpFibers.
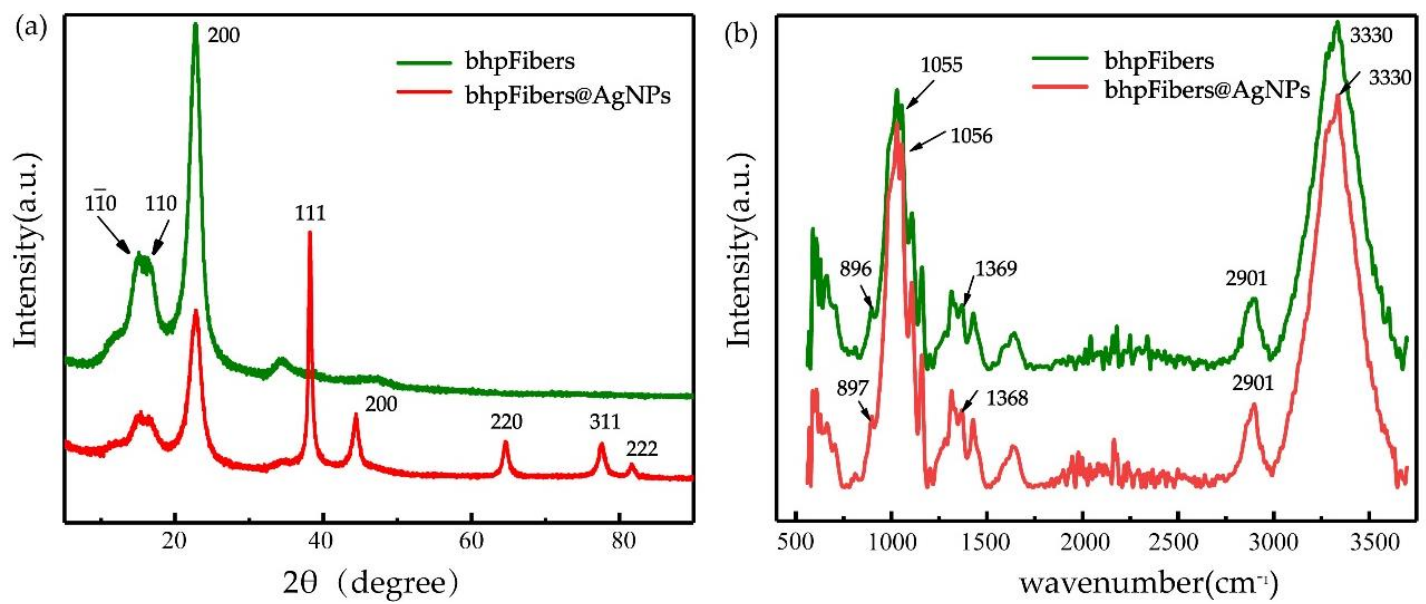

Figure 2. XRD patterns (a) and FT-IR spectra (b) of bhpFibers and bhpFibers@AgNP-based paper.

The structures of the pristine bhpFibers and bhpFibers@AgNP-based paper were investigated by FT-IR in Figure $2 \mathrm{~b}$. As for the pristine bhpFibers, the peak at $3330 \mathrm{~cm}^{-1}$ was attributed to the characteristic absorption of $\mathrm{O}-\mathrm{H}$ stretching. The vibration bands at $2901 \mathrm{~cm}^{-1}$ and $1368 \mathrm{~cm}^{-1}$ can be assigned to the asymmetrical and symmetrical stretching of the $\mathrm{C}-\mathrm{H}$ group, respectively. The absorption band at $1055 \mathrm{~cm}^{-1}$ corresponded to $\mathrm{C}-\mathrm{O}-\mathrm{C}$ stretching mode from the glucosidic units [26]. The peak at $894 \mathrm{~cm}^{-1}$ was related to the $\mathrm{C}-\mathrm{H}$ rocking vibration of cellulose. These bands appeared in both the pristine bhpFibers and the modified cellulose fibers, suggesting the chemical structure of the cellulose was barely changed. No new peaks appeared in the bhpFibers@AgNPs, indicating that the interaction between cellulose fibers and AgNPs was a physical adsorption.

The XPS technique of pristine bhpFibers and bhpFibers@AgNP-based paper could provide further information about the structure and chemical state of AgNPs on cellulose fibers. As depicted in Figure $3 \mathrm{a}$, the pristine bhpFibers showed the binding energy spectra of $\mathrm{C} 1 \mathrm{~s}$ peaks $(288 \mathrm{eV})$ and $\mathrm{O} 1 \mathrm{~s}$ peaks $(533 \mathrm{eV})$, respectively, which can be inferred to lignocellulosic characteristic peaks of cellulose materials [30]. After surface modification, Ag3d peaks were observed in the bhpFibers@AgNPs, demonstrating the formation of AgNPs. A high resolution XPS spectra of Ag3d (Figure 3b) was undertaken to analyze the valence state of $\mathrm{Ag}$ on the surface of cellulose fibers, it can be seen that the peaks of $\mathrm{Ag} 3 \mathrm{~d}_{3 / 2}$ at $368 \mathrm{eV}$ and $\mathrm{Ag} 3 \mathrm{~d}_{5 / 2}$ at $374 \mathrm{eV}$ appeared, demonstrating that the stable zero-valence AgNPs had been successfully loaded on the bhpFibers surface $[43,44]$. 
(a)

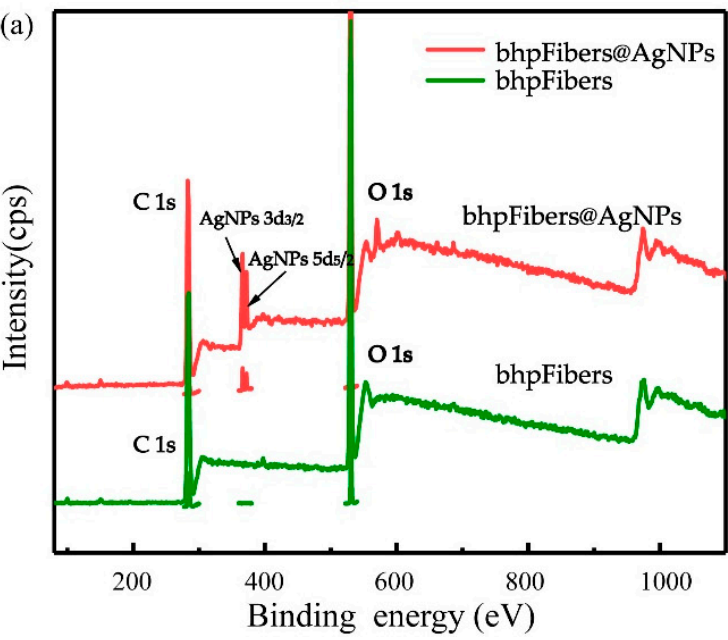

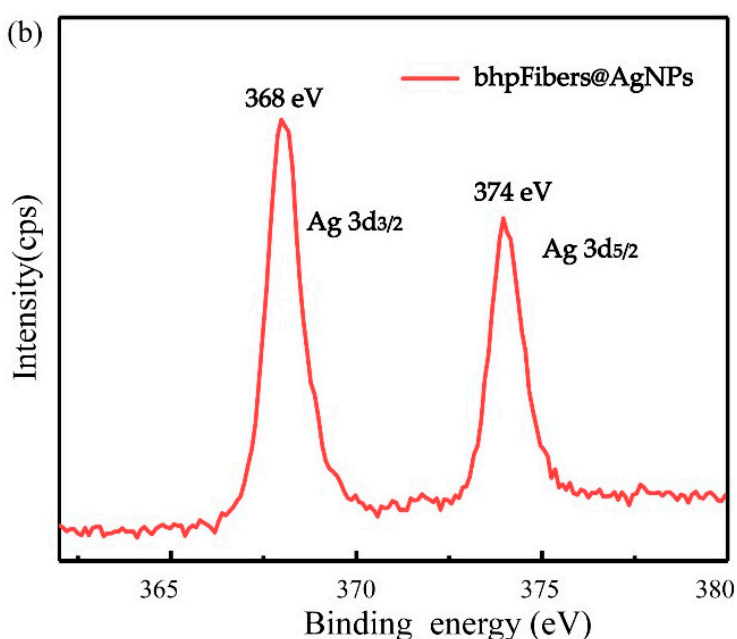

Figure 3. (a) XPS spectra of bhpFibers and bhpFibers@AgNP-based paper; (b) Ag3d XPS spectrum of bhpFibers@AgNP-based paper.

Besides, X-ray energy dispersive spectroscopy mapping (EDS), described in Figure 4, shows that the elements of $\mathrm{C}, \mathrm{O}$ and $\mathrm{Ag}$ were uniformly distributed on the surface of fibers, which also proved that bhpFibers were successfully coated with AgNPs.
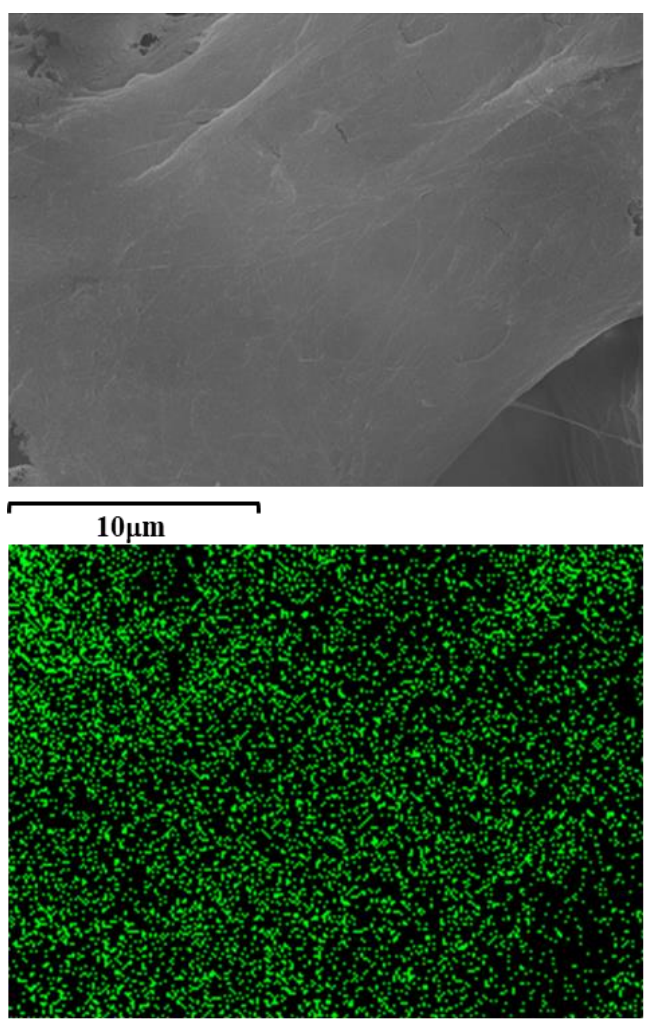

O Ka1

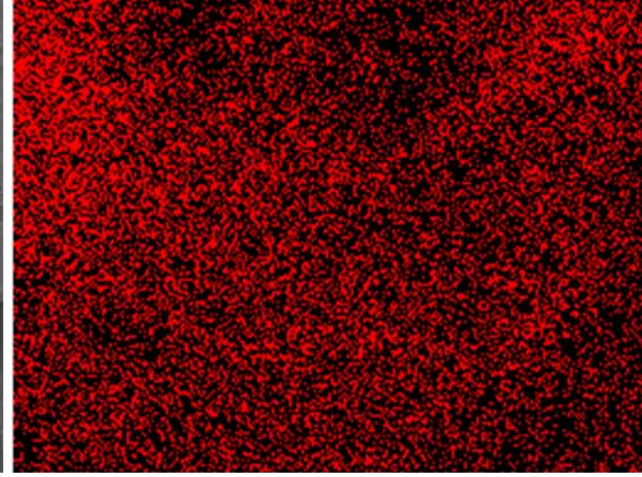

C Ka1_2

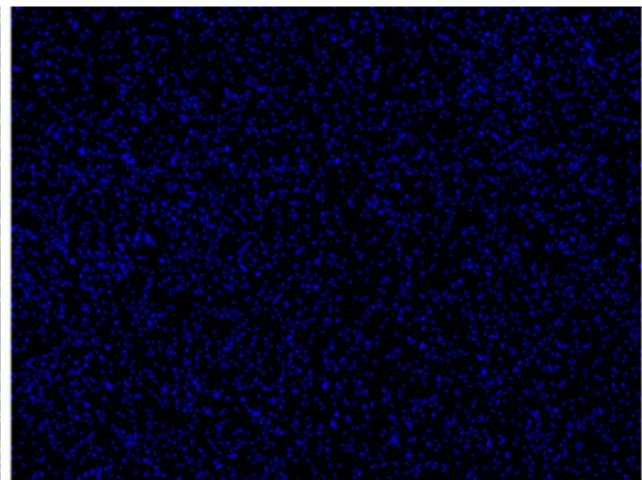

Ag Ka1

Figure 4. EDS elemental mapping images of the bhpFibers@AgNP-based paper.

\subsection{The effect of $\mathrm{AgNO}_{3}$ on the deposition amounts of AgNPs on bhpFibers}

Subsequently, the effects of the concentration of $\mathrm{AgNO}_{3}$ were explored by mixing different concentrations of $\mathrm{AgNO}_{3}(20-80 \mathrm{mM})$ with $0.2 \mathrm{mg} / \mathrm{mL}$ of DLA. As shown in Figure 5, when the concentration of $\mathrm{AgNO}_{3}$ increased from 20 to $80 \mathrm{mM}$, the size of the prepared AgNPs on bhpFibers 
increased slightly from 36.54, 43.86 and 51.75 to $45.05 \mathrm{~nm}$. The AgNPs content in the composites could be determined by the amount of residual at $700{ }^{\circ} \mathrm{C}$ in TGA curves (Figure S2) and the weight percentages of $\mathrm{Ag}$ were calculated to be $9.36 \%, 10.26 \%, 12.91 \%$ and $11.72 \%$, demonstrating that more silver nanoparticles were incorporated into bhpFibers. This result supported the results of the scanning electron microscopy in Figure 5. Moreover, the colour of the obtained papers and ICP-ms analysis of the AgNPs content on bhpFibers was also measured, as shown in Table 1. It can be seen that the paper colour darkened with the AgNPs content when the concentration of $\mathrm{AgNO}_{3}$ was within $60 \mathrm{mM}$. When more $\mathrm{AgNO}_{3}$ (higher than $60 \mathrm{mM}$ ) was added, the impregated AgNPs on the bhpFibers decreased a little. A similar phenomenon was reported for the cellulose/AgNPs membrane [27]. It is noteworthy that all the AgNPs on bhpFibers in Figure 5 were highly dispersed and no visible agglomeration occurred, which was attributed to the strong interaction between hydroxyl and oxygen-containing groups on the cellulose with the AgNPs [40]. According to the above analysis, $60 \mathrm{mM}$ of $\mathrm{AgNO}_{3} \mathrm{was}$ sufficient for achieving the desired silver content on bhpFibers surfaces.
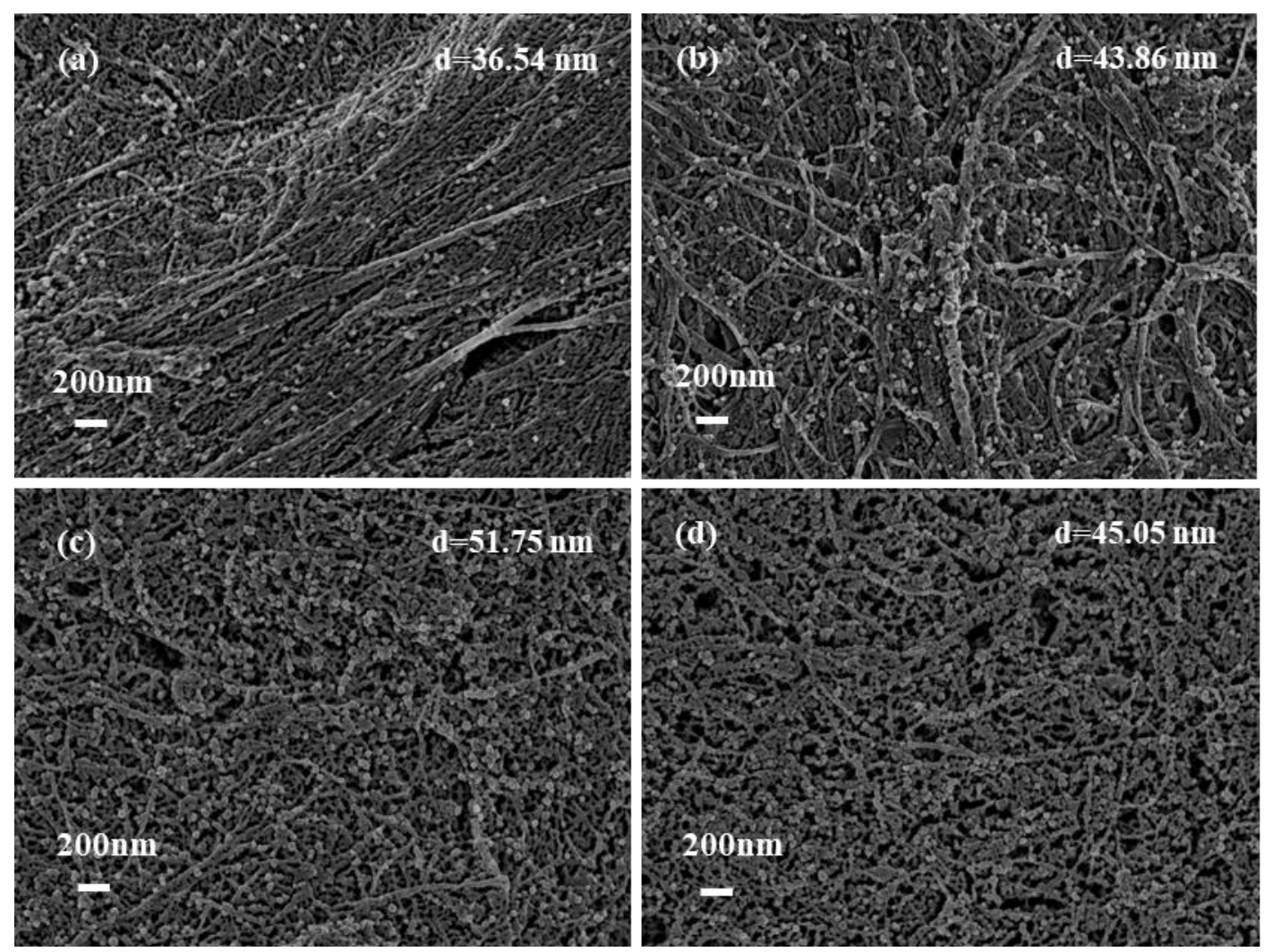

Figure 5. The SEM images (a-d) of bhpFibers@AgNP-based paper prepared by $0.2 \mathrm{mg} / \mathrm{mL}$ DLA and different concentrations of $\mathrm{AgNO}_{3}$ : (a) $20 \mathrm{mM}$, (b) $40 \mathrm{mM}$, (c) $60 \mathrm{mM}$, (d) $80 \mathrm{mM}$.

Table 1. The color and the AgNPs content on the samples.

\begin{tabular}{cccccc}
\hline Sample & bhpFibers & $\begin{array}{c}\text { bhpFibers@Ag } \\
\text { NPs-20 mM }\end{array}$ & $\begin{array}{c}\text { bhpFibers@Ag } \\
\text { NPs-40 mM }\end{array}$ & $\begin{array}{c}\text { bhpFibers@Ag } \\
\text { NPs-60 mM }\end{array}$ & $\begin{array}{c}\text { bhpFibers@Ag } \\
\text { NPs-80 mM }\end{array}$ \\
\hline AgNPs content & 0 & $8.2 \mathrm{mg} / \mathrm{g}$ & $22.4 \mathrm{mg} / \mathrm{g}$ & $33 \mathrm{mg} / \mathrm{g}$ & $31.8 \mathrm{mg} / \mathrm{g}$ \\
Color & & & & & \\
\end{tabular}




\subsection{Antibacterial Properties of bhpFibers@AgNP-Based Paper}

It has been reported that the antibacterial properties of the silver-based nanocomposites are related to the mass of AgNPs in the matrix [24,26]. Herein, the antibacterial activities of bhpFibers@AgNP-based paper prepared by $20 \mathrm{mM}$ and $60 \mathrm{mM} \mathrm{AgNO}_{3}$ were tested on Gram- negative E. coli and Gram-positive S. aureus, respectively. As presented in Figure 6, no inhibition zones were observed nearby the pristine fiber-based papers, indicating that the papers did not show any antibacterial activity. The inhibition zones of the bhpFibers@AgNP-based papers with $20 \mathrm{mM} \mathrm{AgNO}_{3}$ for E. coli and S. aureus were $5 \mathrm{~mm}$ and $3.5 \mathrm{~mm}$, respectively, while the inhibition zones of the bhpFibers@AgNP-based paper with $60 \mathrm{mM}$ silver nitrate for E. coli and S. aureus were $6 \mathrm{~mm}$ and $5 \mathrm{~mm}$. These results demonstrated that the prepared papers showed outstanding antibacterial activity against both E. coli (Gram-negative) and S. aureus (Gram-positive). This is because AgNPs can penetrate the cytoplasm of E. coli and S. aureus, and interact with cell components, causing damage to bacteria. Moreover, with the increasing of AgNPs in papers, the inhibition zones against $E$. coli and $S$. aureus increased simultaneously. These results clearly indicated that the antibacterial ability only stems from the AgNPs impregnating inside bhpFibers. A better antibacterial effect was obtained accompanied by the increase of silver content in the bhpFibers.
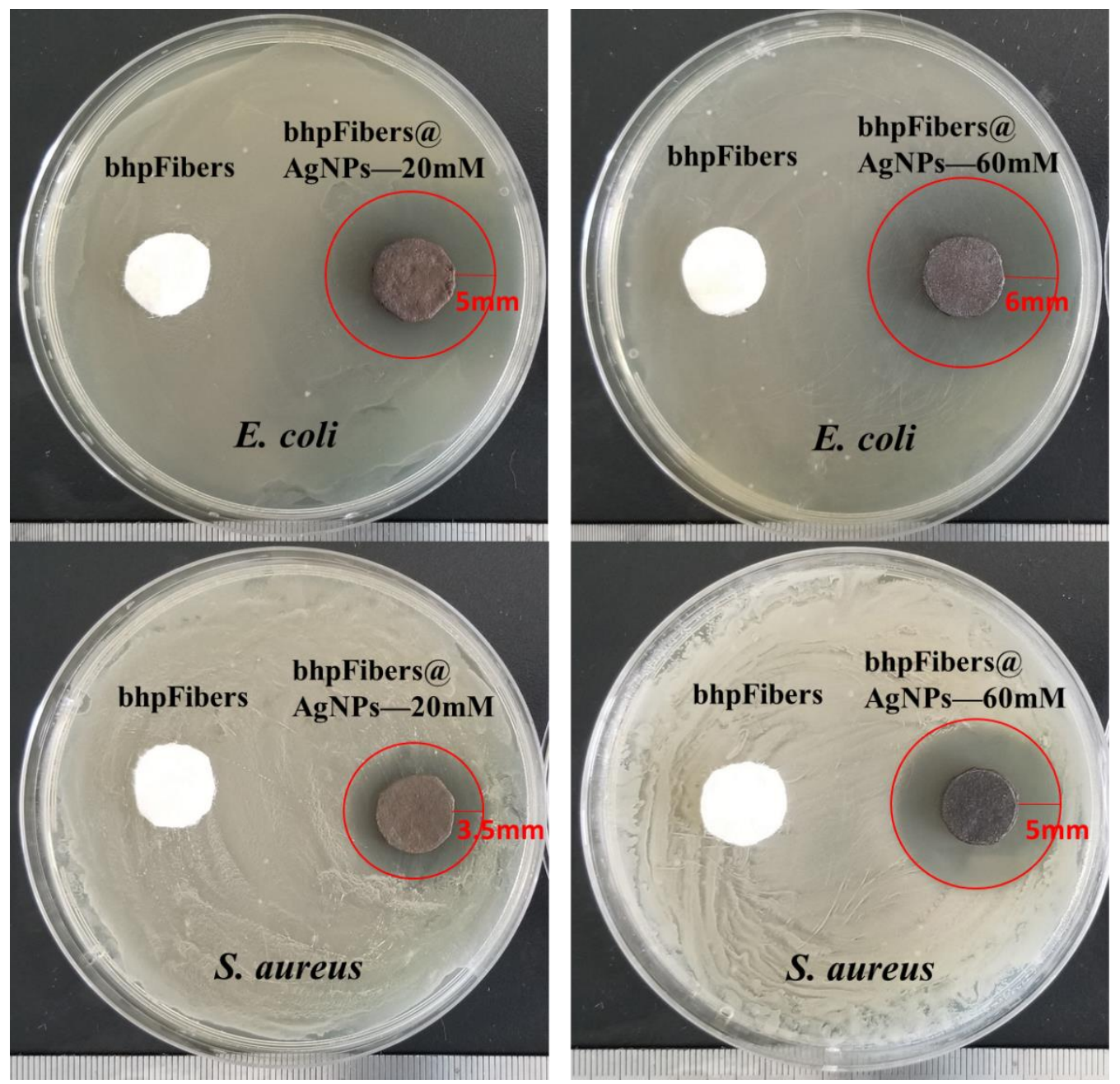

Figure 6. The antibacterial property of bhpFibers and bhpFibers@AgNP-based paper generated using aq. $\mathrm{AgNO}_{3}$ solutions of concentrations 20 and $60 \mathrm{mM}$, respectively, against $E$. coli and S. aureus. 


\section{Conclusions}

In summary, an environmentally benign synthesis method was provided for in situ fabrication of AgNPs on bhpFibers using DLA as the only reducing agent, which was then used for the preparation of antibacterial papers. SEM results indicated that the AgNPs were homogeneously dispersed in the matrix and AgNPs were efficiently synthesized by means of XRD and XPS measurement. FT-IR indicates that the interaction between cellulose fibers and AgNPs was a physical adherence. Different amounts of DLA were introduced and its effect on the size and distribution of AgNPs on the bhpFibers was discussed. It was found that $0.2 \mathrm{mg} / \mathrm{mL}$ DLA was most conducive to the generation of AgNPs with the smallest particle size $(36.27 \mathrm{~nm})$ and uniform distribution. Based on this, a serial of bhpFibers@AgNPs with different amounts of AgNPs were prepared by adjusting the concentration of $\mathrm{AgNO}_{3}$. The results indicate that $60 \mathrm{mM}$ of $\mathrm{AgNO}_{3}$ was sufficient for achieving the desired silver content on bhpFibers surfaces. Moreover, the bhpFibers@AgNP-based paper exhibited outstanding antimicrobial performance against E. coli (gram negative) and S. aureus (gram positive). Therefore, it is believed that this eco-friendly and green synthesis approach for fabrication of the bhpFibers@AgNPs has a promising application in the field of antibacterials.

Supplementary Materials: The following are available online at http://www.mdpi.com/1996-1944/12/19/3101/s1, Figure S1: Size distribution of bhpFibers@AgNPs prepared by $20 \mathrm{mM} \mathrm{AgNO}$ and different concentrations of DLA: (b) $0 \mathrm{mg} / \mathrm{mL}$, (c) $0.1 \mathrm{mg} / \mathrm{mL}$, (d) $0.2 \mathrm{mg} / \mathrm{mL}$, (e) $0.4 \mathrm{mg} / \mathrm{mL}$ and (f) $0.6 \mathrm{mg} / \mathrm{mL}$, Figure S2: TG curves of pristine bhpFibers and bhpFibers@AgNPs prepared by $0.2 \mathrm{mg} / \mathrm{mL}$ DLA and different concentrations of $\mathrm{AgNO}_{3}: 20 \mathrm{mM}$, $40 \mathrm{mM}, 60 \mathrm{mM}$ and $80 \mathrm{mM}$.

Author Contributions: Conceptualization, G.C., Q.W. and X.W.; Methodology, L.Y.; Software, L.Y.; Validation, G.C., X.W. and Q.W.; Formal Analysis, L.Y. and Q.W.; Investigation, L.Y. and Q.Z; Resources, G.C.; Data Curation, L.Y.; Writing-Original Draft Preparation, L.Y. and Q.W.; Writing-Review \& Editing, L.Y. and X.W.; Visualization, L.Y.; Supervision, G.C. and Q.W.; Project Administration, G.C.; Funding Acquisition, G.C.

Funding: This work was supported by the Science and Technology Planning Project of Guangdong Province (No.2017B090901064), the Science and Technology Project of Guangzhou City (No.2016070220045) and the China Postdoctoral Science Foundation (2018M633054).

Conflicts of Interest: The authors declare no conflict of interest.

\section{References}

1. Chao, X.; Xin, W.; Zhu, J. Graphene-Metal Particle Nanocomposites. J. Phys. Chem. C 2008, 112, 19841-19845.

2. Turan, D.; Gunes, G.; Kilic, A. Perspectives of Bio-Nanocomposites for Food Packaging Applications; Springer: Berlin/Heidelberg, Germany, 2018.

3. Yuan, Y.G.; Gurunathan, S. Combination of graphene oxide-silver nanoparticle nanocomposites and cisplatin enhances apoptosis and autophagy in human cervical cancer cells. Int. J. Nanomed. 2017, 12, 6537-6558. [CrossRef]

4. Bardajee, G.R.; Hooshyar, Z.; Rezanezhad, H. A novel and green biomaterial based silver nanocomposite hydrogel: Synthesis, characterization and antibacterial effect. J. Inorg. Biochem. 2012, 117, 367-373. [CrossRef]

5. Xu, Q.; Jin, L.; Wang, Y.; Chen, H.; Qin, M. Synthesis of silver nanoparticles using dialdehyde cellulose nanocrystal as a multi-functional agent and application to antibacterial paper. Cellulose 2019, 26, 1309-1321. [CrossRef]

6. Wu, W.; Zhang, R.; McClements, D.J.; Chefetz, B.; Polubesova, T.; Xing, B. Transformation and Speciation Analysis of Silver Nanoparticles of Dietary Supplement in Simulated Human Gastrointestinal Tract. Environ. Sci. Technol. 2018, 52, 8792-8800. [CrossRef]

7. Choi, S.H.; Lee, K.P.; Park, S.B. Preparation and characterization of poly(ester)-silver and nylon-silver nanocomposites. Stud. Surf. Sci. Catal. 2003, 146, 93-96.

8. Zapataab, P.A.; Páez, M.; Cerda, E.; Azócar, I.; Rabagliati, F.M. Nanocomposites based on polyethylene and nanosilver particles produced by metallocenic "in situ" polymerization: Synthesis, characterization, and antimicrobial behavior. Eur. Polym. J. 2011, 47, 1541-1549. [CrossRef]

9. Hwang, J.J.; Ma, T.W. Preparation, morphology, and antibacterial properties of polyacrylonitrile/montmorillonite/silver nanocomposites. Mater. Chem. Phys. 2012, 136, 613-623. [CrossRef] 
10. Khude, P.; Majumdar, A.; Butola, B.S. Leveraging the Antibacterial Properties of Knitted Fabrics by Admixture of Polyester-Silver Nanocomposite Fibres. Fibers Polym. 2018, 19, 1403-1410. [CrossRef]

11. Rehan, M.; El-Naggar, M.E.; Mashaly, H.M.; Wilken, R. Nanocomposites based on chitosan/silver/clay for durable multi-functional properties of cotton fabrics. Carbohydr. Polym. 2018, 182, 29-41. [CrossRef]

12. Li, Y.; Wang, B.; Sui, X.; Xie, R.; Xu, H.; Zhang, L.; Zhong, Y.; Mao, Z. Durable flame retardant and antibacterial finishing on cotton fabrics with cyclotriphosphazene/polydopamine/silver nanoparticles hybrid coatings. Appl. Surf. Sci. 2018, 435, 1337-1343. [CrossRef]

13. Shi, D.; Wang, F.; Lan, T.; Zhang, Y.; Shao, Z. Convenient fabrication of carboxymethyl cellulose electrospun nanofibers functionalized with silver nanoparticles. Cellulose 2016, 23, 1899-1909. [CrossRef]

14. Boateng, J.; Burgosamador, R.; Okeke, O.; Pawar, H. Composite alginate and gelatin based bio-polymeric wafers containing silver sulfadiazine for wound healing. Int. J. Biol. Macromol. 2015, 79, 63-71. [CrossRef]

15. Chen, H.; Lan, G.; Ran, L.; Xiao, Y.; Yu, K.; Lu, B.; Dai, F.; Wu, D.; Lu, F. A novel wound dressing based on a Konjac glucomannan/silver nanoparticle composite sponge effectively kills bacteria and accelerates wound healing. Carbohydr. Polym. 2018, 183, 70-80. [CrossRef]

16. Xu, Q.; Xie, L.; Diao, H.; Li, F.; Zhang, Y.; Fu, F.; Liu, X. Antibacterial cotton fabric with enhanced durability prepared using silver nanoparticles and carboxymethyl chitosan. Carbohydr. Polym. 2017, 177, 187-193. [CrossRef]

17. Moura, M.R.D.; Mattoso, L.H.C.; Zucolotto, V. Development of cellulose-based bactericidal nanocomposites containing silver nanoparticles and their use as active food packaging. J. Food Eng. 2012, 109, 520-524. [CrossRef]

18. Lu, Y.; Wu, C.; Yang, W.; You, R.; Gang, L.; Chen, Y.; Feng, S. Ag-Coated Cellulose Fibers as Surface-Enhanced Raman Scattering Substrates for Adsorptive Detection of Malachite Green. Materials 2018, 11, 1197. [CrossRef]

19. Junhui, H.; Toyoki, K.; Nakao, A. Facile In Situ Synthesis of Noble Metal Nanoparticles in Porous Cellulose Fibers. Chem. Mater. 2003, 15, 4401-4406.

20. Boumbimba, R.M.; Wang, K.; Hablot, E.; Bahlouli, N.; Ahzi, S.; Avérous, L. Renewable biocomposites based on cellulose fibers and dimer fatty acid polyamide: Experiments and modeling of the stress-strain behavior. Polym. Eng. Sci. 2017, 57, 95-104. [CrossRef]

21. Wang, Q.; Chen, G.; Yu, Z.; Ouyang, X.; Tian, J.; Yu, M. Photoluminescent composites of lanthanide-based nanocrystal-functionalized cellulose fibers for anti-counterfeiting applications. ACS Sustain. Chem. Eng. 2017, 6, 13960-13967. [CrossRef]

22. Wu, J.; Ning, Z.; Zhang, X.; Jian, X. Cellulose/silver nanoparticles composite microspheres: Eco-friendly synthesis and catalytic application. Cellulose 2012, 19, 1239-1249. [CrossRef]

23. Guo, X.Y.; Wang, Q.Q.; Lai, Q.Y.; Ouyang, Q.R.; Li, P.; Yu, H.D.; Huang, W. Biomass-Templated Fabrication of Metallic Materials for Photocatalytic and Bactericidal Applications. Materials 2019, 12, 1271. [CrossRef]

24. Zhu, C.; Xue, J.; He, J. Controlled in-situ synthesis of silver nanoparticles in natural cellulose fibers toward highly efficient antimicrobial materials. J. Nanosci. Nanotechnol. 2009, 9, 3067. [CrossRef]

25. Maria, L.C.D.S.; Santos, A.L.C.; Oliveira, P.C.; Barud, H.S.; Messaddeq, Y.; Ribeiro, S.J.L. Synthesis and characterization of silver nanoparticles impregnated into bacterial cellulose. Mater. Lett. 2009, 63, 797-799. [CrossRef]

26. Li, S.M.; Jia, N.; Ma, M.G.; Zhang, Z.; Liu, Q.H.; Sun, R.C. Cellulose-silver nanocomposites: Microwave-assisted synthesis, characterization, their thermal stability, and antimicrobial property. Carbohydr. Polym. 2011, 86, 441-447. [CrossRef]

27. Yue, X.; Zhang, T.; Yang, D.; Qiu, F.; Li, Z.; Wei, G.; Qiao, Y. Ag nanoparticles coated cellulose membrane with high infrared reflection, breathability and antibacterial property for human thermal insulation. J. Colloid Interface Sci. 2019, 535, 363-370. [CrossRef]

28. Kamel, S. Rapid synthesis of antimicrobial paper under microwave irradiation. Carbohydr. Polym. 2012, 90, 1538-1542. [CrossRef]

29. Li, S.M.; Jia, N.; Zhu, J.F.; Ma, M.G.; Xu, F.; Wang, B.; Sun, R.C. Rapid microwave-assisted preparation and characterization of cellulose-silver nanocomposites. Carbohydr. Polym. 2011, 83, 422-429. [CrossRef]

30. Gong, H.; Liu, M.; Li, H. In situ green preparation of silver nanoparticles/chemical pulp fiber composites with excellent catalytic performance. J. Mater. Sci. 2019, 54, 6895-6907. [CrossRef] 
31. Antony, J.J.; Sivalingam, P.; Siva, D.; Kamalakkannan, S.; Anbarasu, K.; Sukirtha, R.; Krishnan, M.; Achiraman, S. Comparative evaluation of antibacterial activity of silver nanoparticles synthesized using Rhizophora apiculata and glucose. Colloids Surf. B Biointerfaces 2011, 88, 134-140. [CrossRef]

32. Aladpoosh, R.; Montazer, M.; Samadi, N. In situ green synthesis of silver nanoparticles on cotton fabric using Seidlitzia rosmarinus ashes. Cellulose 2014, 21, 3755-3766. [CrossRef]

33. Ramkumar, V.S.; Pugazhendhi, A.; Gopalakrishnan, K.; Sivagurunathan, P.; Saratale, G.D.; Dung, T.N.B.; Kannapiran, E. Biofabrication and characterization of silver nanoparticles using aqueous extract of seaweed Enteromorpha compressa and its biomedical properties. Biotechnol. Rep. 2017, 14, 1-7. [CrossRef]

34. Zhuang, H.; Yang, L.; Zhang, X.X.; Chang, X.W.; Cheng, M.S.; Guo, C. Synthesis of glucuronic acid derivatives via the efficient and selective removal of a C6 methyl group. Tetrahedron Lett. 2016, 58, 423-426.

35. Tajmir-Riahi, H.A. ChemInform Abstract: Sugar Interaction with Silver Ion. Synthesis, Syectroscopic and Structural Analysis of Silver- Glucuronate Compounds. Cheminform 1986, 17, 43-47. [CrossRef]

36. Cui, X.; Chang, M.L.; Bao, H.; Zheng, X.; Guo, J. Hyaluronan-Assisted Photoreduction Synthesis of Silver Nanostructures: From Nanoparticle to Nanoplate. J. Phys. Chem. C 2008, 112, 10730-10734. [CrossRef]

37. Xia, N.; Cai, Y.; Jiang, T.; Yao, J. Green synthesis of silver nanoparticles by chemical reduction with hyaluronan. Carbohydr. Polym. 2011, 86, 956-961. [CrossRef]

38. Gonzalez, J.C.; Garcia, S.; Bellu, S.; Peregrin, J.M.S.; Atria, A.M.; Sala, L.F.; Signorella, S. Redox and complexation chemistry of the Cr-VI/Cr-V/Cr-IV-D-glucuronic acid system. Dalton Trans. 2010, 39, $2204-2217$. [CrossRef]

39. Abhishek, K.; Meeta, G.; Jain, V.K. A novel reusable nanocomposite for complete removal of dyes, heavy metals and microbial load from water based on nanocellulose and silver nano-embedded pebbles. Environ. Technol. 2015, 36, 706-714.

40. Wu, J.; Zhang, F.; Zhang, H. Facile synthesis of carboxymethyl curdlan-capped silver nanoparticles and their application in SERS. Carbohydr. Polym. 2012, 90, 261-269. [CrossRef]

41. Deuber, F.; Mousavi, S.; Federer, L.; Hofer, M.; Adlhart, C. Exploration of Ultralight Nanofiber Aerogels as Particle Filters: Capacity and Efficiency. ACS Appl. Mater. Interfaces 2018, 10, 9069-9076. [CrossRef]

42. Park, S.Y.; Chung, J.W.; Priestley, R.D.; Kwak, S.-Y. Covalent assembly of metal nanoparticles on cellulose fabric and its antimicrobial activity. Cellulose 2012, 19, 2141-2151. [CrossRef]

43. Kang, J.-G.; Sohn, Y. Interfacial nature of Ag nanoparticles supported on TiO2 photocatalysts. J. Mater. Sci. 2012, 47, 824-832. [CrossRef]

44. Cui, J.; Hu, C.; Yang, Y.; Wu, Y.; Yang, L.; Wang, Y.; Liu, Y.; Jiang, Z. Facile fabrication of carbonaceous nanospheres loaded with silver nanoparticles as antibacterial materials. J. Mater. Chem. 2012, 22, 8121-8126. [CrossRef]

(C) 2019 by the authors. Licensee MDPI, Basel, Switzerland. This article is an open access article distributed under the terms and conditions of the Creative Commons Attribution (CC BY) license (http://creativecommons.org/licenses/by/4.0/). 